\title{
Body Mass Index Status of First Year Medical Students
}

\author{
Rahman $\mathrm{MA}^{1}$, Begum $\mathrm{J}^{2}$, Wahab $\mathrm{MA}^{3}$ \\ DOI: https://doi.org/10.3329/jafmc.v16i1.53828
}

\begin{abstract}
Introduction: Body mass index (BMI) is an important tool for indirect measure of nutritional status of an individual. Overweight and obesity are recognized as "escalating epidemics" affecting both developed and developing countries. An obese (BMI $\geq 30$ $\mathrm{kg} / \mathrm{m}^{2}$ ) individual is more likely to get hypertension, heart disease, diabetes mellitus, cardiovascular disease, gall bladder disease and various types of cancer.
\end{abstract}

Aim: To assess the prevalence of overweight and obesity among students of Armed Forces Medical College (AFMC) and factors associated with obesity.

Methods: A descriptive cross-sectional survey was conducted in the Department of Anatomy among 101 students 'AFMC Medical cadets' category from November 2019 to January 2020. Data were collected using pretested questionnaire after taking verbal consent from the participants and administrative authority. The height and weight of the cadets were measured and the BMI was calculated.

Results: Among the 101 Medical cadets of Armed Forces Medical College, the mean \pm SD height of the students was 1.6. $\pm 0.08 \mathrm{~m}$, while the mean weight was $63.6 \pm 12.1 \mathrm{~kg}$ and the mean BMI was $24.0 \pm 4.3 \mathrm{~kg} / \mathrm{m}^{2}$. Normal BMI was observed in $65.6 \%$ students, while $24.2 \%$ students were overweight, $10.1 \%$ obese and only $2.2 \%$ underweight. Overweight and obesity were significantly more in male than female students.

Conclusion: The present study gives an idea about the alarming prevalence of overweight and obesity among the 'AFMC Medical Cadets' category. There is a need to create awareness and interest regarding healthy diet and body weight management among this future physician population. Nutritional education on dietary practices and life style change should be built in as supporting educational activity during each calendar year.

Key-words: Overweight, Obesity, Body mass index (BMI), Medical students, Escalating epidemics.

\section{Introduction}

Body mass index (BMI) is an important tool for indirect measure of nutritional status in an individual. This indicator provides a method that can assist in planning interventions to help eliminate many non-communicable preventable diseases. According to WHO BMl is categorized ${ }^{1}$ as Normal: 18.5 to $<25 \mathrm{~kg} / \mathrm{m}^{2}$, Overweight $\geq 25$ to $<30 \mathrm{~kg} / \mathrm{m}^{2}$ and Obesity $\geq 30 \mathrm{~kg} / \mathrm{m}^{2}$. Obesity can result in a wide range of serious health consequences, such as diabetes, hypertension, cardiovascular disease and some forms of cancer ${ }^{2}$. Overweight and obesity are the fifth leading risk of global deaths ${ }^{3}$, in worldwide, obesity has increased more than doubled since 1980. Now-a- days it has reached epidemic proportions globally. In 2014, more than 1.9 billion adults, aged 18 years and older were overweight and out of them, over 600 million were obese $e^{4}$.

The rapid increase of overweight and obesity, especially in the younger generation, in many low and middle-income countries like Bangladesh, India, Pakistan due to inappropriate diet and inactive lifestyle, foretell us overwhelming non communicable disease burden in the next 10-20 years if no effective measures are taken right now 5 . Graduation period of life is an important stage for adolescents and young adults, as at this time their behaviors are conducive to change ${ }^{6}$ but they are also exposed to stress and lack of time, posing a barrier to adoption of healthy practices ${ }^{7}$ despite being equipped with knowledge. Hence, this study was undertaken to find out the prevalence of over-weight and obesity among the 1st year "AFMC Medical Cadets' category, the undergraduate medical students of AFMC.

\section{Materials and Methods}

This institution based cross sectional study was conducted from November 2019 to January 2020 among 101 first year medical students of 'AFMC Medical Cadets' category. 'AFMC Medical Cadets' category get huge relaxation in physical standard during the admission procedure in contrast to the 'AMC Medical Cadets' category to whom physical standard is as like as the requirement of Bangladesh Armed Forces. Inclusion criteria were all regular male and female cadets. The study group consisted of $89.1 \%$ Bangladeshi, 3.9\% Nepali, 1.9\% Bhutanese and 1.98\% Indian students. AMC Cadets, has been excluded from the study. Although both types of cadets have to go through similar, weekly schedule physical hard ship and other activities. Balanced standard diet is given to compensate the physical hardship and mental stress to all medical cadets. Their heights and weights were recorded and structured questionnaire was filled after getting consent. Z-proportional test was applied to find the significant difference between male and female for each BMI category. Data were analyzed with SPSS 20.0 and a value of $p<0.05$ was considered as statistically significant.

1. Col Md Azizur Rahman, MBBS, MPhil, Professor \& Head, Department of Anatomy, Armed Forces Medical College (AFMC), Dhaka (E-mail: azizur834@yahoo.com) 2. Dr Jebunnessa Begum, MBBS, Junior Consultant of Gynaecology \& Obstetrics, Shahed Ahsanullah General Hospital, Tongi, Dhaka 3. Lt Col Md Abdu Wahab, MBBS, MD, Associate Professor of Biochemistry, AFMC, Dhaka. 


\section{Results}

Among the 101 medical students 37(36.6\%) were male and $64(63.7 \%)$ were female and mean age was $19.6 \pm 0.9$ years. Mean weight of male students was $70.9 \pm 10.5 \mathrm{~kg}$ and for female students $60.5 \pm 12.0 \mathrm{~kg}$. Mean height of male students was $1.7 \pm 0.04$ meter and for female students $1.6 \pm 0.07$ meter. Mean BMI of male students was $23.9 \pm 3.3$ and for female students $23.9 \pm 3.9 \mathrm{~kg} / \mathrm{m}^{2}$. The prevalence of overweight and obese among the male and female together was $23.8 \%$ and $9.9 \%$ respectively. The prevalence of underweight among male and female were $0 \%$ and $3.1 \%$, respectively and the difference between male and female was statistically significant $(p<0.01)$. More than $67 \%$ male and $62 \%$ female students were within normal healthy weight. The prevalence of overweight and obesity among male students were higher than that of female students. Family history of non-communicable disease like; hypertension and diabetes mellitus in either or both of the parent was present in many cadets. This study reveals in either of 53 mothers and 57 fathers of 101 participants were suffering from hypertension and diabetes mellitus respectively. Out of above findings, 15 were common for both the diseases.

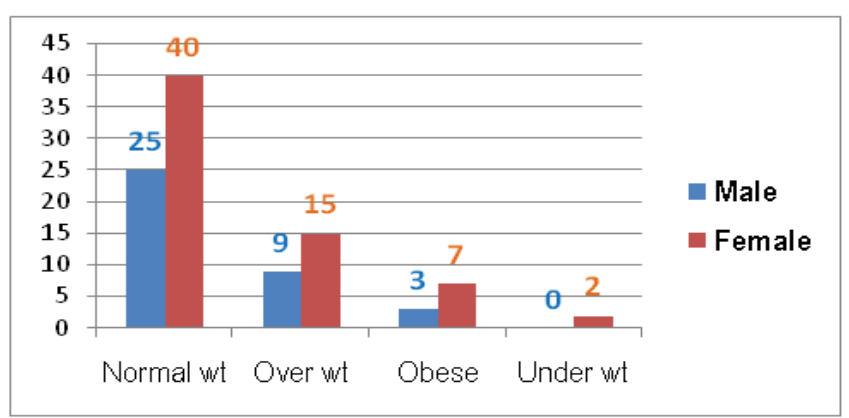

Figure-1: Distribution of participants by gender and BMI

Table-l: Positive family history

\begin{tabular}{|l|c|c|}
\hline Factor & Mother & Father \\
\hline Hypertension & 36 & 32 \\
\hline Diabetes & 17 & 25 \\
\hline
\end{tabular}

\section{Discussion}

Young adult population of a country is an integral part of socioeconomic development and country's future leader in all aspect, so they should be healthy, smart and physically fit. Under the military environment physical fitness of medical cadets is mandatory. More so overweight and obesity is a risk factor in causation of chronic non-communicable diseases therefore increasing the burden of disease. In this study, of the 101 medical cadets, 37 were male and 64 were female students. The mean $\pm S D$ height of the students was $1.6 \pm 0.08 \mathrm{~m}$, the mean weight $63.6 \pm 12.1 \mathrm{~kg}$ and the BMI $23.9 \pm 4.3 \mathrm{~kg} / \mathrm{m}^{2}$. Most (64.36\%) of them showed normal BMI while $23.8 \%$ of them were overweight, $9.9 \%$ obese, and only $1.9 \%$ underweight. The study reveals that the prevalence of overweight and obesity among the medical Cades of AFMC is alarming. Similar study done by
Agrawal S et $a^{4}$ revealsthe mean $\pm \mathrm{SD}$ height of the students were $1.7 \pm 0.09 \mathrm{~m}$, the mean weight $66.6 \pm 12.7 \mathrm{~kg}$ and the BMI $23.5 \pm 3.1$ $\mathrm{kg} / \mathrm{m}^{2}$. Most (73.1\%) of them showed normal BMI while $22.3 \%$ of them were overweight, $3.1 \%$ obese, and only $1.5 \%$ underweight which is very much similar to our findings except the obesity which is lower than that of present study findings.

Rahman MS et $\mathrm{al}^{3}$ in Rajshahi University conducted a study among 911 (male 727 and female 184) university students for investigating their nutritional status, and it was measured by their BMI. The mean BMI of both male $\left(21.6 \pm 2.6 \mathrm{~kg} / \mathrm{m}^{2}\right)$ and female $\left(19.9 \pm 2.6 \mathrm{~kg} / \mathrm{m}^{2}\right)$ students shows the lower prevalence than that of our findingsof BMI of this study. The reason is the cadets of AFMC are from relatively higher socioeconomic background in contrast to the Rajshahi University which is supported by Kotian et $\mathrm{al}^{8}$. They revealed that the risk of obesity was two times higher among the adolescents of high socioeconomic class. A significant relation between obesity and consumption of junk food was established in a study conducted among medical students of Malaysia. In their study, the prevalence of obesity was $15.2 \%$ and that of overweight was $21.8 \%$. This increased prevalence was attributed to their increased junk food consumption ${ }^{9}$. Chhaya and Jadav who carried out their study in a similar population, have reported a higher pro-portion of underweight (13.6\%) and obesity (25.6\%), when compared with this study ${ }^{10}$.

Family history of non-communicable disease like hypertension and diabetes mellitus in either or both of the parent was present in many cadets which is supported by the findings of Agrawal $S$ et $\mathrm{al}^{4}$. All the above findings, reinforcing the need to reschedule the healthy lifestyle, healthy food habits and physical activities in daily routine among the cadets of Armed Forces Medical College.

\section{Conclusion}

This study suggests that limited physical exercise and better medical knowledge about healthy dietary habits does not necessarily result into better practices. The study also shows the prevalence of overweight and obesity among the medical cadets of AFMC is alarming, they need to be encouraged to participate more in physical exercise, especially sports, athletics and other outdoor activities. Further studies should be undertaken to identify specific barriers among medical cadets in practicing healthy dietary habits and come up with workable solutions. Nutrition education is required including counseling on reshaping meals and consumption of snacks.

\section{References}

1) WHO Available at https://www.who.int/mediacentre/factsheets/ fs311/ en/index.html. Accessed on 12 April 2012.

2) Petit CL and Berthelot JM. Obesity-A growing issue. Health Rep 2006; 17:43-50.

3) Rahman MS, Karmaker $\mathrm{H}$, Basar MA et al. Body mass index of University students and gender differentials. Survey in Rajshahi University, Bangladesh. https://www.researchgate.net > publication > 323726878 _Body_Mass_Index. Jun 26, 2018. 
4) Agrawal $S$, Sinha $V$, Kachhawa $P$ et al. Study of body mass index in first year MBBS students in a medical college of Eastern UP. Int J Med Sci Public Health 2017; 6:262-5.

5) World Health Organization. Obesity and Overweight (Fact Sheet). Geneva: World Health Organization. Obesity and Overweight (Fact Sheet), 2015. Available at https://www.who.int/mediacentre/ factsheets/ fs311/en/index.html (last accessed on April 12, 2015)

6) Sajwani AR, Shoukat S, Raza R et al. Knowledge and practice of healthy life-style and dietary habits in medical and non-medical students of Karachi, Pakistan. J Pak Med Assoc 2009; 59(9):650-7.
7) Webb $\mathrm{E}$, Ashton $\mathrm{CH}$, Kelly $\mathrm{P}$ et al. An update on British medical students' lifestyles. J Med Educ 1998; 32:325-31.

8) Kotian MS, Kumar GS, Kotian SS. Prevalence and determi-nants of overweight and obesity among adolescent school children of south Karnataka, India. Indian J Community Med 2010; 35(1):176-8.

9) Gopalakrishnan S, Ganeshkumar P, Prakash MV et al. Prevalence of overweight/obesity among the medical students, Malaysia. Med J Malaysia 2012; 67(4):442-4.

10) Chhaya S, Jadav P. Dietary and lifestyle pattern in relation to overweight and obesity among the medical and nursing students. Indian J Res Rep Med Sci 2012; 2(3):9-12. 